\title{
Produtividade verde-social em uma indústria de esquadrias de alumínio
}

Diante de suas abordagens, as métricas de produtividades ditas 'convencionais' trazem em seu âmago apenas os conceitos econômicos sem incluir em seus cálculos os custos e impactos ambientais e sociais, que se tornam cada vez mais importantes para a subsistência das organizações modernas. Essa nova perspectiva fez surgir alguns modelos de avaliação da produtividade, com destaque para a Produtividade Verde (PV), que ao contrário dos métodos tradicionais de avaliação da produtividade, engloba também os aspectos ambientais, buscando a produção sustentável. Assim, o estudo foi realizado se objetivando mensurar a Produtividade Verde-Social em uma indústria de esquadrias de alumínio. O cálculo do Índice de Produtividade Verde-Social (IPVS) é feito através da relação matemática definida pela razão entre a produtividade (determinada pela razão entre o faturamento e os custos do processo produtivo - dividido em custos de produção, custos ambientais e custos sociais) e os impactos (sociais e ambientais). Para calcular os impactos foram utilizados 62 indicadores tanto para dimensão ambiental como social. O modelo foi testado e aplicado em uma Indústria de Esquadrias de Alumínio (IEA) localizada estado da Paraíba no Nordeste do Brasil, através das variáveis do modelo, o faturamento, todos os custos de produção, ambientais e sociais, e com todos os índices e impactos mensurados com base nos questionários aplicados aos funcionários e a comunidade ao entorno e observação participante. Resultando no primeiro valor de IPVS=0,88 em Indústria de Esquadrias no mundo, faltam dados históricos para efeito de comparação. Conclui-se que o estudo veio contribuir claramente para o avanço da literatura e aplicações reais da PV, mostrandose como uma importante ferramenta de comparação dos parâmetros financeiros e de natureza ambiental e social e excelente indicador na redução dos impactos ambientais e sociais.

Palavras-chave: Aspectos ambientais; Dimensão Social; Produtividade Verde; Indicadores socioambientais; Produção Sustentável.

\section{Green-social productivity in an aluminum frame industry}

In view of their approaches, the so-called 'conventional' productivity metrics bring only economic concepts to their core without including environmental and social costs and impacts in their calculations, which are becoming increasingly important for the survival of modern organizations. This new perspective has given rise to some models of productivity assessment, with emphasis on Green Productivity (PV), which, unlike traditional methods of productivity assessment, also encompasses environmental aspects, seeking sustainable production. Thus, the study was carried out aiming to measure Green-Social Productivity in an aluminum frame industry. The calculation of the Green-Social Productivity Index (IPVS) is done through the mathematical relationship defined by the ratio between productivity (determined by the ratio between revenue and the costs of the production process - divided into production costs, environmental costs and socia costs) and impacts (social and environmental). To calculate the impacts, 62 indicators were used for both the environmental and social dimensions. The model was tested and applied in an Aluminum Frame Industry (IEA) located in the state of Paraíba in Northeast Brazil, through model variables, billing, all production costs, environmental and social, and with all indexes and impacts measured based on questionnaires applied to employees and the community to the surroundings and participant observation. Resulting in the first value of IPVS $=0.88$ in window frames industry in the world, historical data are missing for comparison purposes. It is concluded that the study clearly contributed to the advancement of the literature and real applications of PV, showing itself as an important tool for comparing financial and environmental and social parameters and an excellent indicator in reducing environmental and social impacts.

Keywords: Environmental aspects; Social Dimension; Socio-environmental indicators; Green productivity; Sustainable production.

Topic: Desenvolvimento, Sustentabilidade e Meio Ambiente

Reviewed anonymously in the process of blind peer.
Received: $15 / 03 / 2020$

Approved: $20 / 04 / 2020$

Lucas Vitorino Alves (iD)

Universidade Federal de Campina Grande, Brasil

http://lattes.cnpq.br/1336773416989991

http://orcid.org/0000-0001-6568-8529

lucasvitorino.ep@gmail.com

Viviane Farias Silva (D)

Universidade Federal de Campina Grande, Brasil

http://lattes.cnpq.br/5011520274887172

http://orcid.org/0000-0002-5891-0328

flordeformosur@hotmail.com

\section{José Dantas Neto (ID)}

Universidade Federal de Campina Grande, Brasil

http://lattes.cnpq.br/9137226205129315

http://orcid.org/0000-0003-0798-6717

zedantas1955@gmail.com

\section{Referencing this:}

ALVES, L. V.; SILVA, V. F.; DANTAS NETO, J.. Produtividade verde-social em uma indústria de esquadrias de alumínio. Revista lbero Americana de Ciências Ambientais, v.11, n.3, p.367-383, 2020. DOI:

DOI: 10.6008/CBPC2179-6858.2020.003.0028 


\section{INTRODUÇÃO}

Desde o início da manufatura industrial aos dias atuais, com a acirrada competitividade no mercado e a busca de um novo modelo de crescimento econômico que também considere os aspectos ambientais, as empresas aspiram à otimização de seus sistemas produtivos, objetivando o crescimento da produtividade, redução de custos e consequentemente o aumento dos lucros. Entretanto, as métricas de produtividade denominadas 'convencionais' trazem em seu âmago apenas os conceitos econômicos e não incluem em seus cálculos os custos e impactos ambientais e sociais, tornando as métricas de produtividades convencionais 'mascaradas' ou no mínimo incompletas.

Apesar dos fatores econômicos, sem dúvida, serem de extrema importância para a sobrevivência das organizações, não são os únicos a serem analisados. Os aspectos ambientais e sociais se tornam cada vez mais importante para a subsistência das organizações (GUEDES, 2018). Sob esse ponto de vista, a cobrança perante as organizações empresariais, a busca por novos modelos de indicadores gerenciais, uma mudança na forma de mensurar a produtividade das empresas se fez necessária. Assim, a produtividade vem evoluindo e passando por novos aspectos de mudança, e nesta nova visão, houve a inserção dos conceitos ambientais, assim chamada de Produtividade Verde (PV). Ou seja, a produtividade deixou de ser mensurada focando apenas no aspecto econômico (CAO, 2007).

Dessa maneira, a PV foi criada em 1994 pela APO (Organização de Produtividade da Ásia), para suprir a lacuna encontrada nas métricas convencionais de produtividade, com o objetivo de melhorar a produtividade equilibrando os impactos ambientais e sociais causados pela organização (APO, 2001; HANG et al., 2001; HUR et al., 2004; SAXENA et al., 2003; ZAILANI, 2010).

Entretanto é percebido que a maioria dos estudos sobre PV não incorporam em seus cálculos os impactos e custos sociais, que também compõem o conceito do tripé da sustentabilidade, ou o chamado 'Triple Bottom Line'. A partir dessa lacuna presente na literatura, Fernandes (2016) foi pioneiro no Brasil a criar uma alternativa na forma de mensurar a Produtividade Verde, levando em conta os três aspectos citados, e posteriormente, Guedes (2018) propôs uma nova abordagem adaptada do modelo de Fernandes e a chamou de Produtividade Verde-Social (PVS).

As pesquisas desenvolvidas pelos autores acima citados possuem suas limitações e até o momento só foram aplicadas em uma empresa da indústria calçadista, como no estudo de Fernandes (2016) e em uma empresa da indústria química de poliestireno expandido (EPS), Guedes (2018). Contudo, há grande importância na literatura, por serem os primeiros estudos aplicativos de PV no Brasil, onde é praticamente inexistentes estudos e empresas que conseguem adicionar os aspectos sociais para completar a tríade da sustentabilidade na mensuração da Produtividade. Portanto, esse trabalho pode ser considerado inédito sendo executado com objetivo de mensurar a Produtividade Verde-Social em uma indústria de esquadrias de alumínio situada em um estado do Nordeste do Brasil, a partir da adaptação e aplicação do modelo desenvolvido por Guedes (2018). 


\section{REVISÃO TEÓRICA}

\section{Produtividade e Produtividade Verde}

O significado do termo produtividade é uma das questões mais discutidas dentro da indústria de fabricação, bem como dentro da comunidade de pesquisa, que tem como foco a melhoria de desempenho e medição da produtividade (TANGEN, 2005). De forma geral, a produtividade é definida como sendo uma relação entre os bens produzidos e os fatores que são utilizados para produção, como, tempo, matéria-prima, gerando a quantidade de produto final, ou seja, é a relação entre o que é obtido por unidade econômica e os recursos que essa produção consumiu (CAPUL et al., 1996). Basicamente os pesquisadores a conceituam à luz do seu conceito mais fundamental: a relação entre as entradas e saídas de um sistema Produtividade = Sinputs / Soutputs.

Em 1994, através da APO (Associação de Produtividade da Ásia), surge a Produtividade Verde (PV) objetivando incluir aspectos ambientais (Fernandes e Freitas, 2014), sendo uma ferramenta de gestão que minimiza impactos ambientais, usada especialmente nas pequenas e médias empresas na Ásia (GANDHI et al., 2006; FERNANDES et al., 2014, FERNANDES, 2016; HANG et al., 2001; HUR et al., 2004; ZAILANI, 2010; SAXENA et al., 2003).

Advindo dessa necessidade, a PV nasceu alinhada com a Cimeira da Terra que foi realizado no Rio de Janeiro/BR nos anos de 1992, oriundo das novas perspectivas econômicas e ambientais. Nessa conferência ficou acertado que o desenvolvimento econômico junto com ambiental seriam as bases para a o desenvolvimento sustentável (APO, 2006; SAXENA et al., 2003; HUR et al., 2004; LIN et al., 2013; FERNANDES et al., 2014; FERNANDES, 2016; GUEDES et al., 2018). A Produtividade Verde, do inglês 'Green Productivity', foi criada com o objetivo de auxiliar as organizações. Sua definição formal é criada pela própria associação e é definida como:

Uma estratégia para aumentar a produtividade e o desempenho ambiental para o desenvolvimento socioeconômico geral. É a aplicação de técnicas, tecnologias e sistemas de gerenciamento adequados para produzir bens e serviços ambientalmente compatíveis. A PV pode ser aplicada na fabricação, serviço, agricultura e comunidades. (APO, 2001).

Logo após a APO ter desenvolvido os conceitos estratégico que regem a PV, surgiram na literatura diferentes e novos conceitos de estudiosos e pesquisadores, que vem a somar o conceito inicial ou ainda criar novas perspectivas de estudos. Alguns autores conceituam que a PV é uma estratégia que ocasiona a melhoria da produtividade e do desempenho ambiental tornando o desenvolvimento socioeconômico maior (GANDHI et al., 2006; FERNANDES et al., 2014; FERNANDES (2016); FINDIASTUTI et al., 2011; LI et al., 2015; LI et al., 2013; ZAILANI, 2010; PARASNIS, 2003; SAXENA et al., 2003; TUTTLE et al., 2008).

Na prática, a implementação de PV baseia-se principalmente em conceitos básicos de gerenciamento ambiental para melhorar o desempenho ambiental geral, principalmente em PME's, como: técnicas de minimização de resíduos, prevenção de poluição, reciclagem, reuso; avaliações do ciclo de vida e sistemas de gerenciamento ambiental.

Quando se trata dos benefícios, Fernandes (2016), Li et al. (2015), Cao (2007), Zhang et al. (2014) 
indicam que a implementação da PV pelas empresas, traz benefícios como o aumento da rentabilidade, melhoria da saúde e segurança, melhoria na qualidade dos produtos, maior proteção ambiental, melhoria da imagem da empresa, elevação do moral dos empregados, levando ao desenvolvimento sustentável. Que segundo Parasnis (2003), só são alcançados com o comprometimento e envolvimento da alta administração. Entretanto, são encontradas algumas limitações em estudos sobre PV, sobre tudo a falta de inserção dos aspectos sociais, que é peça fundamental na construção conceitual estabelecida pelo tripé da sustentabilidade.

Desta forma, o estudo realizado por Guedes (2018) destaca dentre várias limitações existentes, que diversos autores não citam ou inserem poucos elementos sociais em suas pesquisas, como: Moharamnejad et al. (2007), Hur et al. (2004), Gandhi et al. (2006), Findiastuti et al. (2011), Lin et al. (2013), Hang et al. (2001), Zailani (2010), Saxena et al. (2003), Deif (2011), Darmawan et al. (2014) e Teniwut et al. (2017). Concluindo que o social é muitas vezes menosprezado pelos pesquisadores, mas que é um elemento fundamentalmente importante da PV e que compõe os princípios do desenvolvimento sustentável.

\section{MATERIAIS E MÉTODOS}

\section{Tipologia da Pesquisa}

Está pesquisa é classificada como sendo de caráter exploratório e descritivo, no que tange a sua finalidade. Para Gil (2008) a pesquisa exploratória tem capacidade de proporcionar uma maior familiaridade com o assunto abordado, normalmente é usada para uma melhor compreensão do assunto estudado, com vistas a torná-lo mais explícito ou a construir hipóteses.

A pesquisa é considerada descritiva devido ao caráter expositivo e busca expor as características de determinada população, fenômeno, etc.. Quanto aos meios, a pesquisa é caracterizada como um estudo de caso, pois se utiliza de uma empresa para realização do cálculo da PVS e seus índices. O estudo de caso é descrito por Gil (2008) como uma análise profunda e exaustiva de um ou poucos objetos, empresas, produtos, que permite um conhecimento amplo e detalhamento do que está sendo foco da pesquisa, e auxilia na melhor compreensão acerca de um problema que não é suficientemente definido, como é o caso da Produtividade Verde-Social.

Os dados foram coletados no ano de 2019 diretamente através de pessoas ou documentos originais cedidos pela empresa localizada no Estado da Paraíba, utilizando-se de instrumentos, como: observação (participante) e a entrevista (semiestruturada), conversas com envolvidos no processo, questionários e consulta documental. Foi aplicado e testado o método desenvolvido por Guedes (2018) em outro seguimento da indústria, haja vista que o estudo relata que o modelo pode ser adaptado as peculiaridades da empresa em estudo, não importando seu seguimento. É importante destacar que esse estudo possui caráter inédito, devido à inexistência de estudos de PVS na indústria de esquadrias de alumínio.

Uma vez definidos os indicadores aplicáveis à Indústria de Esquadrias de Alumínio (IEA), foram realizadas entrevistas com todos os chefes de cada setor da empresa onde os dados foram colhidos, visando 
obter particularidades da fábrica em questão. Também foram aplicados dois questionários adaptados de Guedes (2018) as peculiaridades da indústria em estudo, com objetivo de coletar os dados para avaliação dos indicadores dos impactos ambientais e sociais. O primeiro questionário foi aplicado aos funcionários que trabalham nas instalações fabris (com 18 questões) e o segundo junto à comunidade do entorno (contendo 13 questões), além disso, para entendimento da quantidade de matéria-prima, da produção, desperdício, faturamento, custos ambientais e sociais, através de documentos internos disponibilizado pela empresa.

\section{Modelo De Produtividade Verde-Social}

Para fins deste estudo, será utilizado como base a metodologia de mensuração da PVS de Guedes (2018), desenvolvido em uma indústria química de EPS e segundo o autor pode ser adaptado e aplicado em outros setores industriais. Assim, o Índice de Produtividade Verde-Social (IVPS) pode ser calculado através da Equação 01:

$$
I P V S_{\text {org }}=\frac{\frac{\text { Fat }}{\mathrm{ACT}(\mathrm{CP}+\mathrm{CA}+\mathrm{CS} *)}}{\mathrm{I}(\mathrm{IA}+\mathrm{IS})}
$$

Legenda: Fat - Faturamento Total; ACT - Avaliação Custos Totais; CP- Custos Produção; CA - Custos Ambientais; CS - Custos Sociais; I-Impactos; IA - Impactos Ambientais; IS - Impactos Sociais Fonte: Adaptado de Fernandes (2016).

$\mathrm{Na}$ Equação 01, o custo total de fabricação é dividido em três categorias: custo de produção (CP) que relaciona os custos envolvidos no processo produtivo, custo ambiental (CA) considerado por Eagan e Joeres (2002) como despesas referentes aos impactos ambientais resultantes da manufatura dos produtos e processos da empresa, e o custo social (CS) onde são mensurados os custos relacionados a ações que a empresa faz ou deixa de fazer para com a comunidade, funcionários, instituições, gastos com sindicados, indenizações trabalhista, projetos sociais, dentre outros (GUEDES, 2018).

A análise em separado dos custos é entendida por Fernandes (2016) como uma forma de visualizar como e onde estão sendo gastos ou investidos os recursos monetários da empresa. De um modo geral, este cálculo desenvolvido por Guedes (2018) será adaptado as peculiaridades da IEA estudo de caso e posteriormente aplicado na mesma.

\section{Variáveis do Modelo}

Faturamento nada mais é do que o preço do produto multiplicado pela quantidade de produtos vendidos, muitas vezes possui nomenclatura como 'receita bruta' ou simplesmente 'vendas'. Os custos são importantes indicadores organizacionais que também são utilizados na tomada de decisões empresariais. No Quadro 1, observa-se uma breve revisão de algumas possíveis origens destes três tipos de custos e que podem ser identificados em uma fábrica de esquadrias de alumínio, estudo de caso dessa pesquisa.

Quadro 1: Sintetização dos custos de produção, ambientais e sociais.

\begin{tabular}{|l|ll|}
\hline Tipo & Origem & \\
\hline Custos & - & Aquisição de matérias-primas e equipamentos; \\
Produção & - & Transformação das matérias-primas e materiais auxiliares; \\
\hline
\end{tabular}




\begin{tabular}{|c|c|}
\hline & $\begin{array}{l}\text { Consumo de energia elétrica, água e gás; } \\
\text { Manutenção e reparação de máquinas e equipamentos; } \\
\text { Mão-de-obra diversa; } \\
\text { Aspectos administrativos diversos; } \\
\text { Ineficiência operacional; }\end{array}$ \\
\hline $\begin{array}{l}\text { Custos } \\
\text { Ambientais }\end{array}$ & 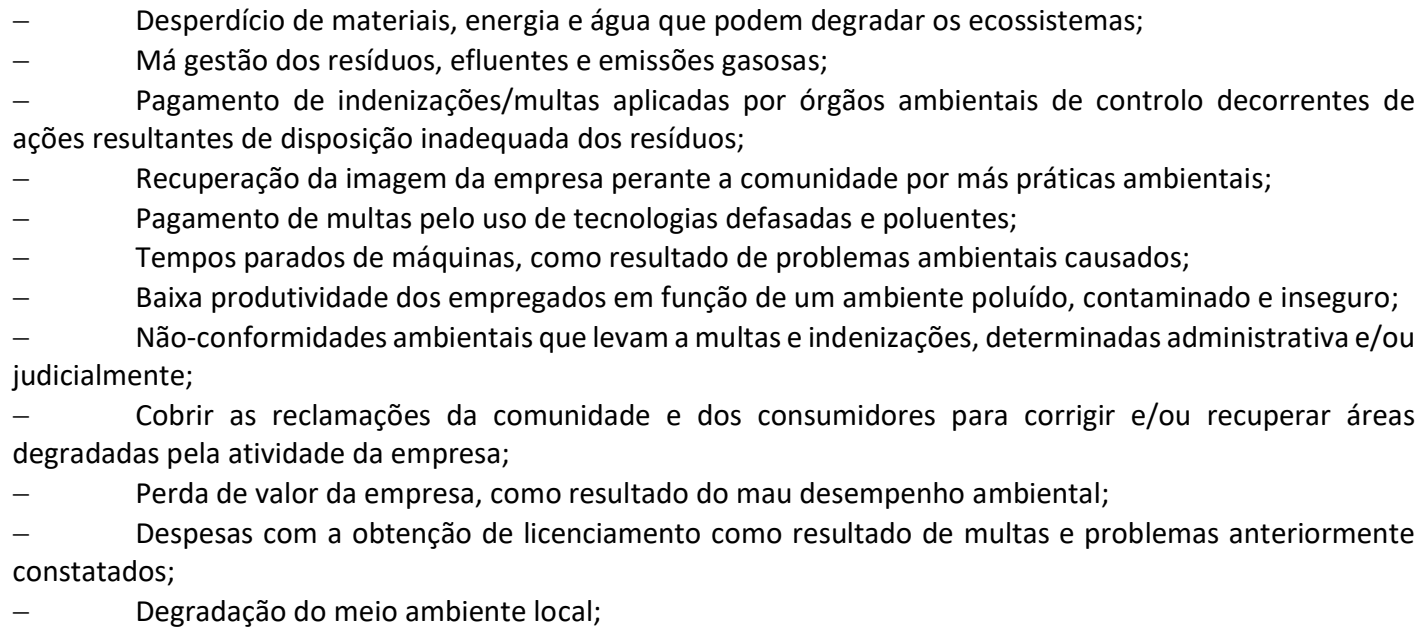 \\
\hline Custos Sociais & 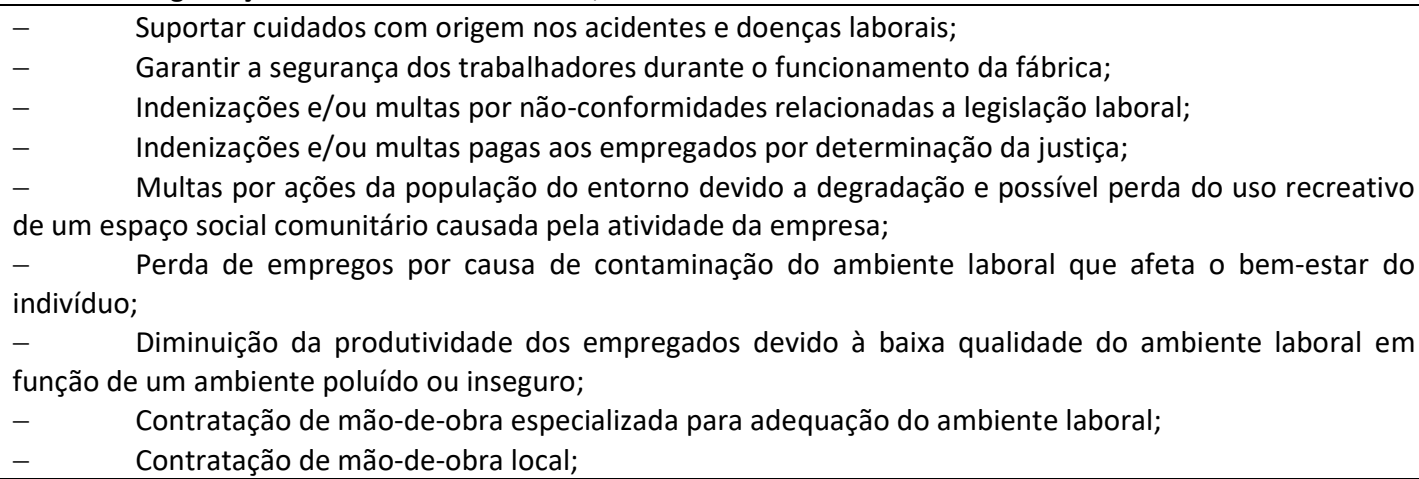 \\
\hline
\end{tabular}

Fonte: Adaptado de Guedes (2018).

\section{Indicadores para avaliação dos impactos ambientais e sociais}

Para mensurar os impactos ambientais, Guedes (2018) elencou 32 indicadores ambientais, cada um avaliado de que foram subdivididos em 5 categorias específicas: Gestão organizacional; matérias-primas; água e energia; subproduto; e comunidade. Dentre estes 32 indicadores, dois não se aplicam ao nosso estudo de caso (A19 e A20) e tivemos que adaptar as peculiaridades da indústria estudada os itens A22 e A27. No item A22 o conceito de resíduos perigosos foi ampliado, pois no estudo de Guedes (2018) tem foco apenas nos óleos e lubrificantes, já no item A27 tomamos como referência os efluentes com origem no consumo de água da empresa, pois a mesma não a utiliza diretamente em seu processo produtivo.

Sequencialmente para mensurar os impactos sociais, foram selecionados 32 indicadores sociais, substanciados em 6 categorias, definidas com: legislação/normas; saúde e segurança; recursos humanos; ambiente de trabalho; comunidade; e clientes/consumidores (GUEDES, 2018). Essa seção levanta ainda aspectos legais de Segurança e Saúde do Trabalho.

Foi aplicado um critério de avaliação para cada indicador, com uma nota de 1 até 3 onde 1 (melhor situação, ou seja, indicador plenamente atendido), 2 (situação mediana, cujo indicador é parcialmente atendido) e 3 (pior situação, que traduz num indicador pouco ou não atendido) conforme a avaliação da indústria de esquadrias de alumínio. Foram selecionados 30 indicadores ambientais e 32 indicadores sociais.

Posteriormente, com os valores atribuídos a cada indicador, os resultados serão atribuídos em uma 
equação de cálculo dos índices que foi definida a partir de Rodrigues et al. (2015), representado pela Equação 02:

$$
\mathrm{I}_{\mathrm{D}}=\frac{\sum N O_{i}}{\sum N P_{i}}(02)
$$

Onde: ID = Valor do índice da dimensão D (podendo ser Ambiental ou Social); $\mathrm{NO}_{\mathrm{i}}=$ Notas obtidas para o indicador $\mathrm{i}($ sendo $\mathrm{i}=1,2, \ldots \mathrm{n})$; $N P_{i}=$ Notas possíveis para o indicador $i$ (sendo $i=1,2, \ldots . n$ )

Fonte: Rodrigues et al. (2015).

Os valores dos índices de cada dimensão (ambiental e social) vão estar em uma escala cujo valores situam-se num intervalo de variação compreendido entre [0; 1], onde: a) quanto mais próximo do valor 0 (zero) o índice obtiver, melhor será a situação da empresa em termos de impactos sobre a dimensão correspondente; ii) quanto mais próximo de 1 (um), pior será sua situação em termos de impactos gerados junto dos sistemas que a empresa opera (FERNANDES, 2016; GUEDES, 2018). Ou seja, se o índice ambiental calculado obter um valor proximo a 1, indica que os processos produtivos da empresa estão ocosionando impactos ambientais degradando o meio ambiente e a empresa não está se posicionando no controle desses aspectos.

Foram realizadas uma simulação utilizando o Microsoft Excel ${ }^{\circledast}$ 2010, mantendo o faturamento e os custos de produção fixos e variando os custos ambientais e sociais. E outra simulação para entender como o IPVS varia com os impactos ambientais e sociais, demais variáveis fixas, como previsto no estudo de (GUEDES, 2018).

\section{RESULTADOS E DISCUSSÃO}

\section{Aspectos Financeiros}

Nesta pesquisa, é importante relatar a peculiaridade da empresa estudo de caso, onde a mesma possui três indústrias diferentes, que juridicamente não possuem nenhuma ligação, mas atuam como fossem uma só ou um grupo, todos seus processos produtivos estão diretamente interligados, assim não podemos estudar as empresas em separado, ou seja, estudar apenas uma delas. Desta forma, tomaremos os aspectos financeiros como uma única empresa, efetuando a soma de seus faturamentos e custos tornando-os únicos.

A união entre as três unidades fabris da IEA no ano de 2019 proporcionou um faturamento que atingiu a cifra dos $\mathrm{R} \$$ 6.215.575,43 e em relação aos custos, despesas e outros pagamentos que a empresa teve que pagar no mesmo ano, Tabela 1, onde pode ser verificada a origem e a diferenciação dos custos em custos de produção (CP), custos sociais (CS) e custos ambientais (CA).

Tabela 1: Discrição dos custos realizados pela IEA, referente ao ano de 2019.

\begin{tabular}{|l|l|l|l|}
\hline \multirow{2}{*}{ Origem dos Custos } & Custos & Sociais (R\$) & Ambientais(R\$) \\
\cline { 2 - 4 } & Produção (R\$) & & \\
\hline Matéria-prima & $394.965,0$ & & \\
\hline Agua & 11.441 & & \\
\hline Energia & $34.702,2$ & & \\
\hline Aluguel & $80.098,42$ & & \\
\hline Manutenção de máquinas instalações físicas & $94.630,15$ & & \\
\hline Mão-de-obra & $1.134 .842,52$ & & \\
\hline Administrativos & $571.894,78$ & & \\
\hline
\end{tabular}




\begin{tabular}{|l|l|l|l|}
\hline Juros & $235.066,44$ & & \\
\hline Impostos & $2.409 .996,04$ & & \\
\hline Fretes/Combustível & $83.414,59$ & & \\
\hline Vendas & $112.887,53$ & & \\
\hline Sindicato & & 342,28 & 278,96 \\
\hline Multas por má gestão ambiental & & & $6.628,03$ \\
\hline Reciclagem & & & \\
\hline Mão de obra especializada de SST (ambiente laboral) & & $3.827,89$ & \\
\hline Indenizações por despedimentos dos funcionários & & $86.927,15$ & \\
\hline Apoio a projetos sociais / ressocialização & & $38.829,61$ & \\
\hline Recuperação da Imagem & & $2.520,49$ \\
\hline Subtotal & & & \\
\hline Total & $5.163 .938,67$ & $129.926,93$ & $9.427,48$ \\
\hline
\end{tabular}

De acordo com a Tabela 01 fica evidente conforme a divisão, que os custos de produção (CP) no referido ano foram de $\mathrm{R} \$ 5.163 .938,67$ e os custos com os eventos ambientais (CA) e com os sociais (CS) foram respectivamente $\mathrm{R} \$ 9.427,48$ e $\mathrm{R} \$ 129.926,93$ que somados totalizam um valor global de custos de $\mathrm{R} \$$ $5.303 .293,08$.

\section{Avaliação Dos Indicadores Ambientais e Cálculo Do Índice Ambiental}

Os indicadores ambientais da categoria Gestão organizacional é composta de 6 indicadores (A1-A6), e a categoria Matéria-Prima também é composta por 6 indicadores (A7-A12) e a pontuação da IEA, conforme a Tabela 2.

Tabela 2: Avaliação das categorias Gestão Organizacional e Matéria-Prima da IEA.

\begin{tabular}{|c|c|c|c|c|c|c|c|}
\hline \multicolumn{4}{|c|}{ Categoria: Gestão Organizacional } & \multicolumn{4}{|c|}{ Categoria: Matéria-prima } \\
\hline \multirow[t]{2}{*}{ ID } & \multirow[t]{2}{*}{ Indicador } & \multicolumn{2}{|l|}{ Nota } & \multirow[t]{2}{*}{ ID } & \multirow[t]{2}{*}{ Indicador } & \multicolumn{2}{|l|}{ Nota } \\
\hline & & Obtida & Possível & & & Obtida & Possivel \\
\hline $\mathrm{A} 1$ & Atendimento a legislação ambiental & 1 & 3 & A7 & Consumo de matéria-prima & 3 & 3 \\
\hline $\mathrm{A} 2$ & Licenciamento ambiental & 1 & 3 & A8 & Economia no uso de matéria-prima & 1 & 3 \\
\hline$A 3$ & Certificações ambientais & 3 & 3 & A9 & Subprodutos reutilizados & 2 & 3 \\
\hline A4 & Estrutura ambiental & 3 & 3 & A10 & Materiais reciclados & 3 & 3 \\
\hline A5 & Capacitação ambiental & 3 & 3 & A11 & Substituição de materiais & 3 & 3 \\
\hline A6 & Processos ambientais & 1 & 3 & A12 & Cadeia suprimentos & 2 & 3 \\
\hline \multicolumn{2}{|c|}{ Subtotal } & 12 & 18 & \multicolumn{2}{|c|}{ Subtotal } & 14 & 18 \\
\hline
\end{tabular}

Analisando os resultados da categoria Gestão Organizacional, percebe-se que obteve 12 pontos dos 18 possíveis, e 3 dos 6 indicadores obtiveram a nota máxima (3) considerada a pior situação e os outros 3 obtiveram a nota mínima 1, sendo a melhor situação estabelecida, assim, a indústria alcançou um desempenho de razoável para ruim, com relação as questões ambientais legais ao meio ambiente.

A segunda categoria está relacionada à 'Matéria-Prima' na IEA, obteve 14 pontos, cerca de 78\%, dos 18 possíveis (Tabela 2). O panorama na categoria de Matéria-Prima é considerado ruim, devido ao aumento no consumo de matéria-prima por parte da empresa, estabelecido pelo aumento de demandas. A mesma, não faz uso de materiais reciclados em sua produção e não leva muito em consideração o quesito meio ambiente, em parcerias com fornecedores e com outros elos da cadeia de suprimentos.

Como ponto positivo, é estabelecido economia de matéria-prima por parte da IEA, através de um sistema de aproveitamento de corte de matéria-prima, visando a redução de custos e o mínimo de desperdício possível no corte do Alumínio. Contando com máquinas de corte e usinagem novas e modernas 
que geram menos desperdícios no processo produtivo, tornando a fábrica mais eficiente em termos de matéria-prima.

Já categoria Água e Energia (A13-A20), como a empresa do estudo de caso não faz uso de gás liquefeito de petróleo (GLP), os indicadores A19 e A20 não se aplicam, sendo alterado assim o total possível a obter 24 para 18. Dos 18 pontos possíveis, a fábrica obteve 13, Tabela 3. A categoria Subprodutos, contendo 7 indicadores (A21-A27), também foram avaliados conforme a Tabela 3.

Tabela 3: Avaliação da categoria Água e Energia e Subprodutos da IEA.

\begin{tabular}{|c|c|c|c|c|c|c|c|}
\hline \multicolumn{4}{|c|}{ Categoria: Água e Energia } & \multirow{3}{*}{ ID } & \multirow{3}{*}{$\begin{array}{l}\text { Categoria: Subprodutos } \\
\text { Indicador }\end{array}$} & & \\
\hline \multirow[t]{2}{*}{ ID } & \multirow[t]{2}{*}{ Indicador } & \multicolumn{2}{|l|}{ Nota } & & & \multicolumn{2}{|l|}{ Nota } \\
\hline & & Obtida & Possível & & & Obtida & Possivel \\
\hline A13 & Consumo de água & 2 & 3 & A21 & Resíduos sólidos & 2 & 3 \\
\hline A14 & Reutilização de água & 3 & 3 & A22 & Resíduos perigosos & 2 & 3 \\
\hline A15 & Redução do consumo de água & 1 & 3 & A23 & Comercialização de resíduos & 1 & 3 \\
\hline A16 & Energia elétrica & 3 & 3 & A24 & Disposição final dos resíduos & 1 & 3 \\
\hline A17 & Economia de energia & 1 & 3 & A25 & Emissões Atmosféricas & 1 & 3 \\
\hline A18 & Energias renováveis & 3 & 3 & A26 & Acidentes ambientais & 1 & 3 \\
\hline A19 & Gás (GLP) & - & - & A27 & Disposição dos efluentes líquidos & 2 & 3 \\
\hline$A 20$ & Economia de gás (GLP) & - & - & \multicolumn{2}{|c|}{ Subtotal } & 10 & 21 \\
\hline \multicolumn{2}{|c|}{ Subtotal } & 13 & 18 & & & & \\
\hline
\end{tabular}

A maior parte da água consumida pela empresa não está ligada diretamente ao processo produtivo, mas é utilizada na diluição de agentes nocivos à saúde como o álcool isopropílico e detergente, dessa forma, não é feita a reutilização da água. No que se refere à energia elétrica, os indicadores A16 e A17, Tabela 03, receberam nota 3 e 1, porque houve uma evolução no consumo de energia oriundo do aumento da produtividade e aquisição de equipamentos, mas que de certa forma consomem menos energia e foram efetuadas ações de melhora na iluminação, como a troca das lâmpadas e utilização de telhas transparentes, bem como a conscientização dos trabalhadores para desligar os equipamentos e lâmpadas quando não estiverem fazendo seu uso.

Tabela 4: Avaliação da categoria Comunidade da IEA.

\begin{tabular}{|l|l|l|l|}
\hline Categoria: Comunidade & Nota \\
\cline { 3 - 4 } & ID & Obtidos & Possíveis \\
\hline A28 & Reclamação da comunidade & 1 & 3 \\
\hline A29 & Minimização das reclamações & 1 & 3 \\
\hline A30 & Educação ambiental & 3 & 3 \\
\hline A31 & Degradação ambiental & 1 & 3 \\
\hline A32 & Premiação ambiental & 3 & 3 \\
\hline Subtotal & & $\mathbf{9}$ & 15 \\
\hline
\end{tabular}

Com relação à categoria 'Subprodutos', a empresa teve seu melhor rendimento, sendo considerados os aspectos, ótimo. Quatro indicadores obtiveram o melhor resultado. Indicando que a indústria possui controle na disposição se seus subprodutos, sejam sólidos ou líquidos, Tabela 3. A última categoria de indicadores ambientais, a categoria 'Comunidade', avalia o desempenho ambiental da IEA, perante a população do entorno (Tabela 4). De acordo com as notas, Tabela 4, nota-se que há uma relação harmoniosa entre a sociedade do entorno e a IEA, entretanto, a mesma não realiza ações junto à comunidade relacionada ao meio ambiente e nem possui certificações ambientais. Com pontuação positiva para os seguintes 
indicadores: reclamação da comunidade; minimização das reclamações e degradação ambiental. Enquanto que a Educação ambiental e Premiação ambiental tiveram uma classificação ruim, devido não haver nenhum trabalho ambiental voltado a comunidade.

$\mathrm{Na}$ Tabela 5, constata-se o resultado dos indicadores ambientais por categoria obtidos pela IEA. O Índice Ambiental (IA) de 0,64 da IEA indica a uma situação considerada razoável, quando se refere aos impactos ambientais. O baixo valor do IA, pode ser entendido por a empresa dá pouca importância aos aspectos ambiental.

Tabela 5: Índice Ambiental da Indústria de Esquadrias de Alumínio.

\begin{tabular}{|l|l|l|}
\hline Categoria dos Indicadores & Nota Obtida $\left(\mathbf{N O}_{\mathbf{i}}\right)$ & Nota Possível $(\mathbf{N P} \mathbf{i})$ \\
\hline Gestão Organizacional & 12 & 18 \\
\hline Matéria-Prima & 14 & 18 \\
\hline Água e Energia & 13 & 18 \\
\hline Subprodutos & 10 & 21 \\
\hline Comunidade & 9 & 15 \\
\hline Total & 58 & 90 \\
\hline Índice Ambiental $(\mathrm{IA})=\frac{\sum N O_{i}}{\sum N P_{i}}$ & 0,64 & \\
\hline
\end{tabular}

A empresa estudada não possui nenhuma certificação ambiental, e a falta de incentivos governamentais pode ser um ponto importante para obtenção de certificados. Não são realizados trabalhos com os funcionários ou a comunidade relativa a questão ambiental. Entretanto, a indústria tenta do seu modo não poluir o meio ambiente, fazendo a reciclagem dos principais resíduos de seu processo produtivo, o alumínio e o vidro.

\section{Avaliação dos Indicadores Sociais e Cálculo do Índice Social}

Seguindo a mesma lógica dos indicadores ambientais, os Indicadores Sociais (IA) são apresentados por suas categorias e respectivos indicadores. Deste modo, a primeira categoria a ser estudada foi a de 'Legislação e Normas' (S1-S5), que considera em seu quadro de indicadores as legislações trabalhistas, apoio ao consumidor, processos trabalhistas, entre outros (Tabela 6). Na segunda categoria de indicadores 'Saúde e Segurança' (S6-S10), trata da avaliação de aspectos relacionados a saúde e segurança dos trabalhadores (Tabela 6).

Está categoria obteve bons resultados, Tabela 06, retratando bem que a empresa preserva a legislação trabalhista, garantindo ao funcionário todos os direitos trabalhistas vigentes através da Consolidação das Leis do Trabalho (CLT), ainda possui um Programa de Prevenções de Riscos Ambientais (PPRA) posto em prática e uma excelente pós-venda. Embora, existiram alguns processos trabalhistas em meio a órgãos públicos referente a trabalhadores que estavam executando atividades sem estarem legalmente regularizados pela empresa e a CIPA não é atuante, por isso os indicadores S1 e S4 obtiveram nota parcial (2).

A categoria Saúde e Segurança com bons resultados, nota 7, igualmente a primeira categoria Legislação e Normas. Este resultado está relacionado a prática anual de exames médicos periódicos que estão estipulados na NR-7 (exames admissionais, demissionais e anuais), porém ocorreram alguns acidentes de 
trabalho com afastamento temporário, em parte, devido inconsistência e a falta de treinamentos de prevenção e controle de riscos para todos os funcionários, visando a minimização ou mesmo eliminação de acidentes no trabalho (AT) e doenças laborais, Tabela 6.

Tabela 6: Avaliação das categorias Legislação e Normas e Saúde e Segurança da IEA.

\begin{tabular}{|c|c|c|c|c|c|c|c|}
\hline \multirow{3}{*}{ ID } & \multicolumn{3}{|l|}{ Categoria: Legislação e Normas } & \multirow{3}{*}{ ID } & \multirow{3}{*}{$\begin{array}{l}\text { Categoria: Saúde e Segurança } \\
\text { Indicador }\end{array}$} & \multirow{2}{*}{\multicolumn{2}{|c|}{ Nota }} \\
\hline & \multirow[t]{2}{*}{ Indicador } & \multicolumn{2}{|l|}{ Nota } & & & & \\
\hline & & Obtida & Possível & & & Obtida & Possível \\
\hline S1 & $\begin{array}{l}\text { Comissão interna de prevenção de } \\
\text { acidentes (CIPA) }\end{array}$ & 2 & 3 & S6 & Acompanhamento médico & 1 & 3 \\
\hline $\mathrm{S} 2$ & Legislações trabalhistas & 1 & 3 & S7 & Doenças do trabalho & 1 & 3 \\
\hline S3 & $\begin{array}{l}\text { Programa de prevenção de riscos } \\
\text { ambientais }\end{array}$ & 1 & 3 & S8 & $\begin{array}{l}\text { Treinamento em saúde } \\
\text { ocupacional }\end{array}$ & 1 & 3 \\
\hline S4 & Processos trabalhistas & 2 & 3 & S9 & Acidentes de trabalho & 2 & 3 \\
\hline S5 & Apoio ao consumidor & 1 & 3 & S10 & $\begin{array}{l}\text { Redução de acidentes de } \\
\text { trabalho }\end{array}$ & 2 & 3 \\
\hline \multicolumn{2}{|c|}{ Subtotal } & 7 & 15 & \multicolumn{2}{|c|}{ Subtotal } & 7 & 15 \\
\hline
\end{tabular}

A terceira categoria, Ambiente de trabalho (S11-S15), traz 5 indicadores relacionando o ambiente laboral da indústria e os funcionários e a categoria Recursos humanos (S16-S24) e suas receptivas notas. (Tabela 7). Neste item, sem dúvida, a percepção dos trabalhadores é ainda mais relevante, pois são eles que estão expostos aos riscos existentes no ambiente de trabalho e a utilização do decibelímetro para medição do ruído nas instalações fabris no item S11.

A partir da análise da Tabela 7, ficam evidentes as reclamações frequentes escutadas e vivenciadas pelo pesquisador durante seu período de vivência na empresa. Estas reclamações estão relacionadas à má qualidade do ambiente laboral oriundas de altos níveis de ruídos e temperaturas elevadas, principalmente nas áreas de corte, montagem, expedição e estoque de perfis.

Em relação ao ruído a NR-15 cita 85 decibéis máximos para 8 horas de trabalho diário, porém, em algumas máquinas chegam a $88 \mathrm{db}$ indicando para apenas 5 horas de trabalho diária. Dados coletados através da empresa consultora (SESI-PB), que mediu os níveis de ruídos na indústria. Quanto ao conforto térmico, as áreas de montagem, expedição e armazenamento de perfis, possuem temperaturas altas principalmente das 10 às 15 horas, devido à grande exposição ao sol que os galpões recebem e por possuírem má circulação do ar. Agravando a situação, a maioria dos locais não possui equipamentos para circulação do ar e os que se tem estão quebrados ou precisando de manutenção. Por estes aspectos, os indicadores S11, S12 e S14 foram avaliados com nota 3, Tabela 7.

Já a categoria Recursos humanos, foi mal avaliada e a explicação dada pela gerencia é a 'a crise' enfrentada pela Indústria da Construção Civil (ICC), devido a IEA ser muito dependente da demanda dessa indústria, Tabela 7. A ICC passou por anos de glória entre 2010 a 2015, e de baixas entre os anos 2018 a 2018, nos últimos anos a indústria vem tendo seu crescimento retomado aos poucos, muitos empresários ainda estão cautelosos em suas negociações. Desta forma, a IEA tem obedecido a níveis de crescimento baixos, similares ao da Construção Civil. Assim, nos últimos 3 anos a empresa em estudo teve que enxugar o quadro de funcionários e reduzir gastos para poder conseguir se manter no mercado. De modo geral a categoria de Recursos Humanos houve notas altas e nenhum índice obteve êxito em sua avaliação com a nota (1). 
Concluindo que a empresa precisa investir melhor no seu recurso humano, pois são eles que movimentam a empresa, Tabela 7.

Tabela 7: Avaliação da categoria Ambiente de trabalho e Recursos humanos da IEA.

\begin{tabular}{|c|c|c|c|c|c|c|c|}
\hline \multirow{3}{*}{ ID } & \multicolumn{3}{|l|}{ Categoria: Ambiente de Trabalho } & \multicolumn{4}{|c|}{ Categoria: Recursos humanos } \\
\hline & \multirow[t]{2}{*}{ Indicador } & \multicolumn{2}{|l|}{ Nota } & \multirow[t]{2}{*}{ ID } & \multirow[t]{2}{*}{ Indicador } & \multicolumn{2}{|l|}{ Nota } \\
\hline & & Obtida & Possível & & & Obtida & Possível \\
\hline S11 & Níveis de Ruídos & 3 & 3 & S16 & Geração de emprego & 3 & 3 \\
\hline S12 & Ambiente Laboral & 3 & 3 & S17 & Progressão salarial & 3 & 3 \\
\hline S13 & $\begin{array}{l}\text { Exposição a produtos químicos, } \\
\text { óleo e lubrificantes }\end{array}$ & 2 & 3 & S18 & Política de empregabilidade & 3 & 3 \\
\hline S14 & Reclamação dos funcionários & 3 & 3 & S19 & Pagamento de salários & 2 & 3 \\
\hline S15 & Espaço de convivência & 2 & 3 & S20 & Decisões laborais & 2 & 3 \\
\hline \multicolumn{2}{|c|}{ Subtotal } & 13 & 15 & S21 & Desligamento dos funcionários & 2 & 3 \\
\hline & & & & S22 & Rotatividade dos funcionários & 2 & 3 \\
\hline & & & & S23 & Capacitação Profissional & 3 & 3 \\
\hline & & & & S24 & $\begin{array}{l}\text { Capacitação Profissional oferecida } \\
\text { pela empresa }\end{array}$ & 2 & 3 \\
\hline & & & & Subt & & 22 & 27 \\
\hline
\end{tabular}

As próximas categorias são Comunidade (S25-S30) e Clientes/Consumidores (S31-S32), e seus indicadores estão presentes na Tabela 08. A categoria 'Comunidade' tem seus indicadores referentes ao relacionamento da indústria com população do entorno. A partir da análise da Tabela 08, observa se que três indicadores receberam nota (3): investimento em ações sociais, programa de voluntariado e procedência dos funcionários. Essa má avaliação é decorrente do não investimento da empresa em ações sociais e programas voluntários que integrem a comunidade e os funcionários. No quesito procedência dos funcionários S27, menos da metade dos funcionários são oriundos do bairro onde está localizada a empresa, em parte esse resultado pode ser explicado, pois o bairro onde a empresa está inserida é considerado uma área fabril, mas existe uma comunidade carente próximo as instalações da empresa.

Tabela 8: Avaliação das categorias 'Comunidade' e 'Clientes/Consumidores' da IEA.

\begin{tabular}{|l|l|l|l|l|l|l|l|l|}
\hline \multicolumn{2}{|l|}{ Categoria: Comunidade } & \multicolumn{3}{l|}{ Comunidade: Clientes/consumidores } \\
\hline ID & Indicador & ID & Indicador & \multicolumn{2}{l|}{ Nota } \\
\cline { 3 - 4 } & & Obtida & Possível & & & Obtida & Possível \\
\hline S25 & Investimento em ações sociais & 3 & 3 & S31 & Qualidade do Produto & 2 & 3 \\
\hline S26 & Programa de voluntariado & 3 & 3 & S32 & Retorno de Produtos & 2 & 3 \\
\hline S27 & Procedência dos funcionários & 3 & 3 & Subtotal & 4 & 6 \\
\hline S28 & Parceria com instituições & 2 & 3 & & & & \\
\hline S29 & Reclamações da comunidade & 1 & 3 & & & & \\
\hline S30 & Inclusão das reclamações & 1 & 3 & & & & \\
\hline Subtotal & $\mathbf{1 3}$ & 18 & & & & \\
\hline
\end{tabular}

O indicador S28 obteve a nota (2), pois a empresa já participou do programa de ressocialização de presos, com o objetivo de contribuir para a recuperação social de sentenciados, por meio da capacitação profissional, Tabela 08. Não foram constatadas reclamações da comunidade perante as atividades da empresa, assim não foi preciso que a mesma realizasse alguma melhoria oriunda de reclamações feitas pela população do entorno. Desta forma os itens S29 e S30 tiveram nota (1).

Por fim, temos a categoria Clientes/Consumidores, Tabela 8 , que busca medir a relação entra a empresa e seus clientes/consumidores. Todos dois indicadores qualidade do produto (S30) e retorno de produtos (S31) obtiveram nota (2) em sua avaliação. A esquadria fabricada pela empresa, por ser um produto 
considerado de auto nível, tem que atender e garantir todas as normas vigentes de qualidade, segurança e também a sua estética. Contudo, já houve um incidente com uma janela de um edifício, gerando reclamações de clientes.

Após a avaliação de todos os indicadores em suas respectivas categorias baseado na coleta de dados feita em entrevistas, questionário e vivência do pesquisador, resultou no Índice Social (IS) da IEA (Tabela 09). O Índice Social (IS) de 0,69 indica uma situação razoável para ruim dessa empresa em termos de impactos sociais. O resultado indica que a empresa precisa melhorar suas ações voltadas aos aspectos sociais principalmente nos indicadores das categorias 'Ambiente de Trabalho' e 'Recursos Humanos' que logram os piores resultados entre as categorias e também nenhuma das notas dos indicadores foram 1, ou seja, todos indicadores cumprem em partes ou não são cumpridos pela empresa.

Ao final da análise dos indicadores ambientais (IA) e sociais (IS) da Indústria de Esquadrias de Alumínio que obteve 0,64 e 0,69 respectivamente, observa se que seus valores se encontram próximos a 1 , ou seja, a empresa possui muitos pontos que precisam ser explorados e melhorados para serem reduzido os impactos tanto ambientais como sociais.

Tabela 9: Participação das categorias de indicadores na composição do Índice Social da Indústria de Esquadrias de Alumínio.

\begin{tabular}{|l|l|l|}
\hline Categoria dos Indicadores & Nota Obtida $\left(\mathbf{N O}_{\mathbf{i}}\right)$ & Nota Possível $\mathbf{( \mathbf { N P } _ { \mathbf { i } } )}$ \\
\hline Legislação e Normas & 7 & 15 \\
\hline Saúde e Segurança & 7 & 15 \\
\hline Ambiente de trabalho & 13 & 15 \\
\hline Recursos Humanos & 22 & 27 \\
\hline Comunidade & 13 & 18 \\
\hline Clientes/Consumidores & 4 & 6 \\
\hline Total & 66 & 96 \\
\hline Índice Social= $\frac{\sum N O_{i}}{\sum N P_{i}}$ & $\mathbf{0 , 6 9}$ & \\
\hline
\end{tabular}

De fato, pode se afirmar que a empresa causa impactos negativos ao meio ambiente e a sociedade, em especial quando se trata de sua matéria prima no quesito ambiental e ao ambiente laboral e aos recursos humanos nos aspectos sociais.

\section{Índice de Produtividade Verde-Social}

Em posse dos valores de faturamento, custos de produção, ambiental, social e os índices ambientais e sociais, além da determinação da fórmula de IPVS, determinando o Índice de Produtividade Verde-Social, cujo valor encontrado foi de 0,88 , conforme apresentado na Tabela 10 . O custo ambiental (CA) que é de R\$ 9.427,48 corresponde aproximadamente apenas $0,18 \%$ do custo total da empresa, Tabela 10 . Ou seja, a empresa gasta quase nada no que tangem os aspectos ambientais se comparado os custos totais ou faturamento anual. O insignificante investimento que a empresa faz na área ambiental é refletido nos impactos ambientais (IA) que podem causar danos irreversíveis ao meio ambiente.

Quanto aos custos sociais (CS) obtiveram maiores gastos, assumindo um valor de $\mathrm{R} \$ 129.926,93$ cerca de 14 vezes maior do que o investido aos custos ambientas, segundo a Tabela 10. O CS representa uma bagatela de apenas $2,4 \%$ do total do custo produtivo são investidos em soluções sociais que englobam não 
só a sociedade do entorno, mas principalmente os próprios funcionários da empresa, assim a indústria deveria possuir mais investimentos de forma a melhorar a qualidade de vida da sociedade de seus funcionários.

Tabela 10: Valores das variáveis de cálculo do IPVS da Indústria de Esquadrias de Alumínio

\begin{tabular}{|l|l|}
\hline Variáveis & Valores \\
\hline Faturamento (Fat) & $\mathrm{R} \$ 6.215 .575,43$ \\
\hline Custos de Produção & $\mathrm{R} \$ 5.163 .938,67$ \\
\hline Custos Ambientais & $\mathrm{R} \$ 9.427,48$ \\
\hline Custos Sociais* & $\mathrm{R} \$ 129.926,93$ \\
\hline Custos ACT (CP+CA+CS+) & $\mathrm{R} \$ 5.303 .293,08$ \\
\hline Índice Ambiental (IA) & 0,64 \\
\hline Índice Social (IS) & 0,69 \\
\hline $\mathrm{I}(\mathrm{IA}+\mathrm{IS})$ & 1,33 \\
\hline \multicolumn{1}{c|}{ Fat } & $\mathbf{0 , 8 8}$ \\
\hline \multirow{2}{*}{$\mathrm{ICT}(\mathrm{IA}+\mathrm{IS})$} & \\
\hline
\end{tabular}

Quando relacionamos os CA e CS, pode ser notado um baixo valor proporcionando apenas 2,25\% do faturamento da empresa, a empresa precisa investir de forma eficiente para poder mitigar ou eliminar os impactos ambientais e sociais. Esses baixos custos encontrados demonstram que a empresa quase não sofreu ou não sofreu punições severas ambientalmente e socialmente, pois os custos despendidos pela mesma são considerados baixos perante as punições. Isso pode ter ocorrido devido a IEA em estudo está se enquadrando nas legislações vigentes, apesar de necessitar aprimoramento, como foi notado, ou a falta de fiscalização constante.

\section{Simulação do IPVS}

É importante lembrar que esse é o primeiro valor de IPVS em indústria de esquadrias no mundo, assim faltam dados em literatura para efeito de comparação e entendimento pleno do significado do IPVS. O valor da IPVS de 0,88 é uma produtividade instantânea, isto é, um retrato do que está acontecendo no momento. Foi feita uma primeira simulação utilizando o Microsoft Excel ${ }^{\circledast}$ 2010, mantendo o faturamento e os custos de produção fixos e variando os custos ambientais e sociais, Figura 1, como previsto no estudo de (GUEDES, 2018).

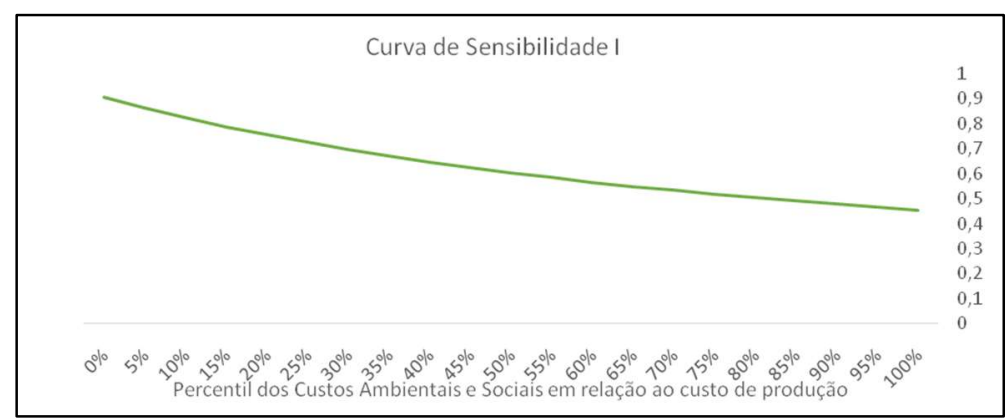

Figura 1: Curva de sensibilização do IPVS da IEA por variação de custos ambientais e sociais.

O eixo $X$ representa o percentil de variação dos custos ambientais e sociais em relação ao faturamento (GUEDES, 2018). Para melhor compreensão, será exemplificado três situações possíveis, duas delas em casos extremos: (i) No primeiro caso extremo, quando o valor do eixo X for '0\%', corresponde como 
se a empresa não gastasse nada com o ambiente e a sociedade, e quando observado no eixo $\mathrm{Y}$ o valor do IPVS seria '0,905', isto é, a produtividade seria de 0,905 a maior possível neste caso; (ii) Já o valor de '25\%' no eixo $X$ refere-se a se fosse gasto com o ambiente e a sociedade $25 \%$ do que foi gasto com a produção desta forma obteríamos no eixo Y uma produtividade de 0,724 ; (iii) No segundo caso extremo, se colocarmos os custos com o ambiente e sociedade iguais com o custo de produção, ou seja, $X=C P=100 \%$ obteríamos um IPVS de aproximadamente '0,453'.

Desta forma, a curva de sensibilidade do IPVS na indústria de esquadrias de alumínio estudo de caso, possibilita enxergar que o melhor índice possível de produtividade seria 0,905, um excelente resultado produtivo, se a empresa não gastasse nada com o ambiente e a sociedade, porém para Guedes (2018) isso seria um retrocesso ao século XX, quando as empresas produziam de forma desenfreada e não ligavam com os aspectos ambientais e nem sociais, tinham em mente apenas a visão do lado econômico.

Pelo outro extremo se os custos ambientais e sociais fossem iguais ao custo de produção, o IPVS da indústria de esquadrias cairia para o valor de 0,403 , valor bem abaixo do habitual para sobrevivência das organizações. Guedes (2018) questiona: "qual empresa real sobreviveria a tão pouca produtividade?". Raramente as organizações sobreviveriam a índices tão baixos de produtividade abaixo dos $50 \%$. Uma segunda simulação é aplicada nesse estudo para entender como o IPVS da indústria de esquadrias de alumínio varia de acordo com os impactos ambientais e sociais, e fixando as outras variáveis (Figura 2).

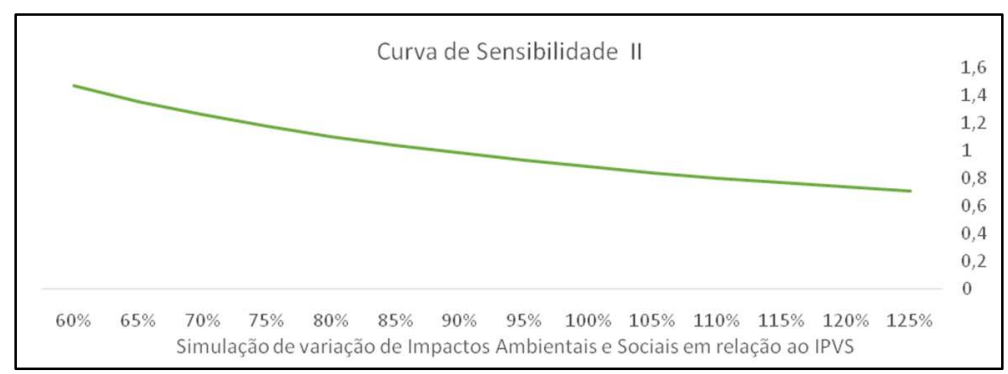

Figura 2: Curva de sensibilização do IPVS da Indústria de Esquadrias de Alumínio por variação dos impactos ambientais e sociais.

A curva de sensibilidade (Figura 02) foi simulada considerando o valor real dos impactos da indústria de esquadrias estudo de caso 1,33, obtido pela soma dos IA e IS, como sendo 100\% como recomendado por Guedes (2018). Para entendermos melhor vamos exemplificar: (i) Entende se pelo marco de referência o valor de $100 \%$, se observar no eixo para direita $15 \%$ (ou seja, aumentar o impacto real em $15 \%$ ) o valor referido ao IPVS que era de 0,88 cai para 0,77 , referente a uma queda de ou $12,5 \%$ da produtividade; (ii) De forma contrária, se observar para esquerda 15\% (diminuindo o impacto ambiental em 15\%) o IPVA aumenta para 1,04 , ou seja, a produtividade aumenta aproximadamente de $18 \%$ do valor real tomado como referência. Com esse gráfico é possível visualizar o quanto a empresa perde ou ganha com o aumento ou redução dos impactos sociais e ambientais. Assim auxiliando os gestores nas tomadas de decisões e indicando que devem atuar nas respectivas variáreis mal avaliadas. 


\section{CONCLUSÕES}

Os indicadores ambientais (IA) e sociais (IS) da Indústria de Esquadrias de Alumínio que obteve 0,64 e 0,69 respectivamente, valores próximos a 1, estando classificada de razoável tendendo a ruim, necessitando melhorias em suas categorias; O valor da IPVS de 0,88 é uma produtividade instantânea, isto é, um retrato do que está acontecendo no momento e valor real dos impactos da indústria de esquadrias estudo de 1,33 .

A partir das simulações pode se afirmar que empresa quando for aumentando os Custos Ambientais e Custos Sociais, a produtividade iria caindo, se a produtividade cair muito se torna inviáveis os gastos ambientais e sociais. Porém, na segunda simulação quando reduzem os impactos ambientais e sociais, a empresa terá um ganho acentuado na produtividade. Sendo assim uma importante ferramenta gerencial na tomada de decisões.

Como limitações e dificuldades do estudo, destaca se a dificuldade em fazer a separação dos custos de produção, ambientais e sociais das atividades produtivas da empresa, onde a mesma e inúmeras empresas não possuem uma separação adequada de seus custos de produção e principalmente dos custos ambientais e sociais. Assim, conclui se que a Produtividade Verde-Social e suas métricas de mensuração podem ser consideradas como uma importante estratégia e também ferramenta, rumo às práticas empresariais sustentáveis, porém, ainda é preciso muita reflexão e debate para solidificação da PVS.

\section{REFERÊNCIAS}

APO. Asian Productivity Organization. Green Productivity Practices in Select Industry Sectors. Tokyo: APO, 2001.

APO. Asian Productivity Organization. Handbook on Green Productivity. Ottawa: APO, 2006.

CAO, J.. Measuring Green Productivity Growth for China's Manufacturing Sectors: 1991-2000. Asian Economic Journal, v.4, n.21, p. 425- 451, 2007.

CAPUL, J.; GARNIER, O.. Dicionário de economia e de ciências sociais. Lisboa: Plátano, 1996.

DARMAWAN, M. A.; MARIMIN, M. MACHFUD, M.; PUTRA, M. P. I. F.. Value chain analysis for green productivity improvement in the natural rubber supply chain: a case study. Journal of Cleaner Production, v.85, p.201-211, 2014.

DEIF, A.. A system model for green manufacturing. Advances in Production Engineering and Management, v.6, n.1, p.2736, 2011.

EAGAN, P. D.; JOERES, E.. The utility of environmental impact information: a manufacturing case study. Journal of Cleaner Production, Oxford, v.10, p.75-83, 2002.

FERNANDES, L.. Um modelo de mensuração da produtividade verde: uma proposta para organizações da indústria de fabricação de calçados. Tese (Doutorado em Recursos Naturais) - Universidade Federal de Campina Grande, Campina Grande, 2016.
FERNANDES, L.; FREITAS, L.. Da Produtividade à Produtividade Verde: Reflexões sobre a evolução conceitual rumo à sustentabilidade. Revista Espacios, v.35, p.2, 2014.

FINDIASTUTI, W.; ANITYASARI, M.; SINGGIH, M.. Green Productivity index: Do Different Terns Measure the Same Things?. Proceeding of Industrial Engineering and Service Science, 2011.

GANDHI, M.; SELLADURAI, V.; SANTHI, P.. Green productivity indexing: A practical steptowards integrating environmental protection into corporate performance, International Journal of Productivity and Performance Management. v.55, n.7, p.594-606, 2006.

GIL, A.. Como elaborar projetos de pesquisa. 4 ed. São Paulo: Atlas, 2008. DOI: https://doi.org/10.1108/13683040510634835

GUEDES, F. C. V.. Produtividade verde - social em uma indústria química de poliestireno expandido (EPS). Dissertação (Mestrado em Engenharia de Produção) Universidade Federal da Paraíba, João Pessoa, 2018.

GUEDES, F.; SILVA, R.; FERNANDES, N.. Estudo da arte da produtividade verde. In: ENCONTRO NACIONAL DE ENGENHARIA DE PRODUÇÃO, 37. Anais. Joinville: ENEGEP, 2017.

HANG, N.; HONG, N.. Sustainability of Green Productivity Implementation at Community Level: A Case Study of 
Vietnam. In: INTERNATIONAL CONFERENCE OF GREENING OF INDUSTRY NETWORK, 9. Anais. Bangkok, 2001.

HUR, T.; KIM, I.; YAMAMOTO, R.. Measurement of green productivity and its improvement. Journal of Cleaner Production, v.12, n.7, p.673-683, 2004.

LI, K.; LIN, B.. Measuring green productivity growth of Chinese industrial sectors during 1998-2011. China Economic Review, v.36, p.279-295, 2015.

LIN, E.; CHEN, P.; CHEN, C.. Measuring green productivity of country: A generalized metafrontier Malmquist productivity index approach. Energy, v.54, p.1-14, 2013.

MOHARAMNEJAD, N.; AZARKAMAND, S.. Implementation of green productivity management in airline industry. International Journal of Environment Science Technology, v.4, n.1, p.151-158, 2007.

PARASNIS, M.. Green Productivity in Asia and the Pacific Region. International Energy Journal, v.4, n.1, 2003.

RODRIGUES, A. M.; ZEVIANI, C. H.; REBELATO, M. G.; BORGES, L.. Avaliação de desempenho ambiental industrial: elaboração de um referencial metodológico. Revista Produção, Florianópolis, v.15, n.1, p.101-134, 2015.

SAXENA, A. K.; BHARDWAJ, K. D.; SINHA, K. K.. Sustainable growth through green productivity: a case of edible oil industry in India. International Energy Journal, v.4, n.1, p.81-91, 2003.

TANGEN, S.. Demystifying productivity and performance. International Journal of Productivity and Performance Management, v.54, n.1, p.34-46, 2005. DOI: https://doi.org/10.1108/17410400510571437

TENIWUT, Y.; MARIMIN, M.; INDRASTI, N.. Spatial intelligent decision support system for increasing productivity on natural rubber agroindustry by green productivity approach. International Journal of Productivity and Performance Management, v.66, n.6, p.742-765, 2017.

TUTTLE, T.; HEAP, J.. Green productivity: moving the agenda, International Journal of Productivity and Performance Management, v.57, n.1, p.93-106, 2008.

ZAILANI, S.. Factors Influencing the Implementation of Green Productivity Pratices and its Effect on the Organisational Performance: A Comparision Study Between EMS 14001 and ISO 9000 Certified Companies in Malaysia. Asian Journal of Information Technology, v.9, n.2, p.45-53, 2010.

ZHANG, Y.; JIN, P.; FENG, D.. Does civil environmental protection force the growth of China's industrial green productivity? Evidence from the perspective of renteseeking. Ecological Indicators, v.51, p.215-227, 2014.

A CBPC - Companhia Brasileira de Produção Científica (CNPJ: 11.221.422/0001-03) detém os direitos materiais desta publicação. Os direitos referem-se à publicação do trabalho em qualquer parte do mundo, incluindo os direitos às renovações, expansões e disseminações da contribuição, bem como outros direitos subsidiários. Todos os trabalhos publicados eletronicamente poderão posteriormente ser publicados em coletâneas impressas sob coordenação da Sustenere Publishing, da Companhia Brasileira de Produção Científica e seus parceiros autorizados. Os (as) autores (as) preservam os direitos autorais, mas não têm permissão para a publicação da contribuição em outro meio, impresso ou digital, em português ou em tradução. 